\title{
The epidemiology and clinical features of calcaneus osteomyelitis following calcaneus fracture: a retrospective study of 127 cases
}

\author{
Kai Huang, Qiaofeng Guo, Yansheng Zhu \\ Department of Orthopedics, Tongde Hospital of Zhejiang, Hangzhou, China \\ Contributions: (I) Conception and design: Y Zhu; (II) Administrative support: Y Zhu; (III) Provision of study materials or patients: All authors; (IV) \\ Collection and assembly of data: K Huang; (V) Data analysis and interpretation: K Huang; (VI) Manuscript writing: All authors; (VII) Final approval \\ of manuscript: All authors. \\ Correspondence to: Yansheng Zhu. Department of Orthopedics, West Ward of 5th Floor, 2nd Building, Tongde Hospital of Zhejiang, 234 Gucui Road, \\ Xihu District, Hangzhou 310012, China. Email: sltdzys@163.com.
}

Background: To analyze the epidemiology and features of calcaneus osteomyelitis following open reduction and internal fixation (ORIF) after closed calcaneus fracture.

Methods: We retrospectively analyzed 127 cases who were diagnosed with calcaneal osteomyelitis following ORIF via the extended lateral "L-shaped" approach after closed calcaneus fracture between March 2016 and August 2019 in our hospital. We analyzed participant demographics including gender, age, body mass index (BMI), trauma mechanism, Sanders classification, co-morbidity, time between initial injury and surgery, operating time, soft tissue stripping tools, tourniquet pressure, bone grafting option, internal fixation option, presence of bleeding after tourniquet deflation, and drainage option.

Results: The majority of cases ( $n=127)$ were male (4.5 times more than female gender), at a ratio of 4.47:1. Falling from height was the main trauma mechanism (79.53\%), followed by traffic accident (14.17\%), and jumping $(6.3 \%)$. A total of 51 cases $(40.16 \%)$ were left-side fractures, and $76(59.84 \%)$ were right-sided. According to the Sanders classification, 12 cases were type II (9.45\%), 61 cases were type III (48.03\%), and 54 cases were type IV (42.52\%). There were 25 participants with the co-morbidity of type 2 diabetes mellitus (19.69\%), 7 with hypertension (5.51\%), and 1 case each of psoriasis and sicca syndrome (0.8\%). The mean time to surgery was 4.7 days (4-9 days), and 123 participants $(96.85 \%)$ were treated within 7 days. The mean operating time was $102.1 \mathrm{~min}(75-135 \mathrm{~min})$. Forty-four participants $(34.65 \%)$ received the conventional scalpel and 83 participants $(65.35 \%)$ the electric scalpel during soft tissue stripping intraoperatively. The mean tourniquet pressure was $432.3 \mathrm{mmHg}(350-550 \mathrm{mmHg})$. Autologous bone grafting was observed in 6 cases (4.72\%), allograft bone grafting in 11 cases (8.67\%), and OsteoSet grafting in 7 cases $(5.51 \%)$. A locking plate was used in 114 cases (89.76) while anatomical plate in 13 cases (10.24\%). A total of 27 participants $(21.26 \%)$ bled after tourniquet deflation. Drainage tubes were applied in 30 participants $(23.62 \%)$ while rubber drainage strips in 5 participants (3.94\%).

Conclusions: Young males dominated the calcaneus osteomyelitis following traumatic calcaneus fracture cohort in this study. A fall from height was the most frequent trauma mechanism. The presence of severe calcaneus fracture, Sanders type III (48.03\%) and type IV (42.52\%), were the common fracture types in this population group.

Keywords: Epidemiology; clinical features; calcaneus osteomyelitis; open reduction and internal fixation; retrospective studies

Submitted Jan 08, 2021. Accepted for publication Mar 16, 2021.

doi: 10.21037/apm-21-208

View this article at: http://dx.doi.org/10.21037/apm-21-208 


\section{Introduction}

Calcaneus fracture is a common clinical event that accounts for about $0.4-2 \%$ of all fractures and approximately $60-75 \%$ of tarsal bone related fractures (1-3). It remains difficult to manage surgically due to the irregular anatomical shape similar to cuboid, varied thickness of the surrounding soft tissues, and poor blood supply, resulting in burden of living quality and health care. Soft tissue involvement is related to this high-energy injury, and intra-articular fracture might present the worst outcomes $(4,5)$.

The optimal intervention of calcaneus fracture currently remains controversial. Dhillon et al. reported that open reduction and internal fixation (ORIF) through a lateral approach could afford the possibility of weightbearing without pain in daily life (5). Simultaneously, the improvement of computerized tomography (CT) has assisted in the extensive application of this surgical protocol that has been considered the standard of treatment options (6). Some surgeons are in favor of this surgical protocol on account of its capacity to restore calcaneal morphology and anatomic reduction of the articular surface (1).

However, complications following ORIF should not be neglected and osteomyelitis is one of the possible sequelae of calcaneus injury (7). Osteomyelitis is a challenging complication that composes $3-11 \%$ of all bone infections (8). Even though the treatment of osteomyelitis has been standardized as surgical debridement, intravenous antibiotic therapy, and/ or reconstruction (7), it can still lead to devastating disorders like loss of function, altered gait, partial or total calcanectomy, amputation, and even more severe, death (9). It is critical to prevent the occurrence of osteomyelitis proactively, thus leading us to retrospectively study 127 hospitalized patients diagnosed with calcaneus osteomyelitis following ORIF after closed calcaneus fracture (March 2016 to August 2019). We analyzed the epidemiology and identified the characteristics of calcaneus osteomyelitis following closed calcaneus fracture, and hoped to gain an understanding of its clinical features to develop the base of knowledge for treatment and prevention of calcaneus osteomyelitis.

We present the following article in accordance with the STROBE reporting checklist (available at http://dx.doi. org/10.21037/apm-21-208).

\section{Methods}

From March 2016 to August 2019, a total of 127 patients diagnosed with calcaneal osteomyelitis following routine extended lateral "L-shaped" approach for ORIF after calcaneus fracture in our hospital were recruited to this retrospective study. We excluded patients with conserved fracture, severe systemic disease, and psychosis. The surgical procedures were performed by five experienced senior surgeons. Participant data including age, gender, medical history, and co-morbidities were collected from clinical records and verified by a telephone interview. The trauma mechanism and operative details were gathered from the in-hospital records, and the relative symptoms of calcaneal osteomyelitis were collected from medical records. Evidence of calcaneal osteomyelitis was obtained from laboratory physicians and radiologists blinded to the participants' information.

An existing co-morbidity was defined as a participant having any of the following: type 2 diabetes mellitus, hypertension, psoriasis, or sicca syndrome. All procedures performed in this study involving human participants were in accordance with the Declaration of Helsinki (as revised in 2013). The study was approved by Ethics committee of Tongde Hospital of Zhejiang Province (No.: 2015016). Individual consent for this retrospective analysis was waived.

\section{Statistical analysis}

Statistical analysis was performed using SPSS 19.0 software (IBM, USA) and figures were created by OriginaLab 9.0 (OriginLab Corporation., USA). Measurement data were presented as mean, median and range. Counting Data were presented as frequency (percentage).

\section{Results}

The overall duration of calcaneus osteomyelitis among participants was 6-23 months, with an average of 14.3 months. The demographic data of calcaneus fracture are shown in Table 1. There were 104 (81.89\%) males and 23 (18.11\%) females, aged 22-82 years, with a mean age of 46.8 years. All participants were diagnosed as unilateral closed fracture (left: 51; right: 76). The mean BMI was 25.2 (17.9-36.9). Of the 127 participants, 101 (79.53\%) fractures resulted from a fall, 18 (14.17\%) from traffic accidents, and 8 (6.3\%) from jumping (Figure 1). The CT imaging results showed, according to the Sanders classification, 12 (9.45\%) fractures were in type II, 61 (48.03\%) were in type III and, 51 (42.52\%) were in type IV (Figure 2). Among the 127 cases, 25 (19.69\%) had the co-morbidity of type 2 diabetes mellitus, 7 (5.51\%) of hypertension, $1(0.8 \%)$ of psoriasis, and $1(0.8 \%)$ of sicca 
Table 1 Participant demographics

\begin{tabular}{|c|c|}
\hline Demographic & $\begin{array}{c}\text { Value } \\
(\mathrm{n} / \text { mean, median and range) }\end{array}$ \\
\hline \multicolumn{2}{|l|}{ Gender } \\
\hline Male & $104(81.89)$ \\
\hline Female & $23(18.11)$ \\
\hline Age(y) & $46.8 / 45 /[22-82]$ \\
\hline BMI & 25.2/25.5/(17.9-36.9) \\
\hline \multicolumn{2}{|l|}{ Etiology } \\
\hline Fall & $101(79.53)$ \\
\hline Traffic accident & $18(14.17)$ \\
\hline Jumping & $8(6.3)$ \\
\hline \multicolumn{2}{|l|}{ Fracture side } \\
\hline Left & $51(40.16)$ \\
\hline Right & $76(59.84)$ \\
\hline \multicolumn{2}{|l|}{ Sanders classification } \\
\hline Type II & $12(9.45)$ \\
\hline Type III & $61(48.03)$ \\
\hline Type IV & $54(42.52)$ \\
\hline \multicolumn{2}{|l|}{ Accompanied pathology } \\
\hline Type 2 diabetes mellitus & 25 (19.69) \\
\hline Hypertension & $7(5.51)$ \\
\hline Psoriasis & $1(0.8)$ \\
\hline Sicca syndrome & $1(0.8)$ \\
\hline Without & 93 (73.2) \\
\hline Time to surgery (d) & $4.7 / 5 /[2-9]$ \\
\hline Operating time (min) & $102.1 / 100 /[75-135]$ \\
\hline \multicolumn{2}{|l|}{ Stripping tools of soft tissue } \\
\hline Conventional scalpel & 44 (34.65) \\
\hline Electronic scalpel & $83(65.35)$ \\
\hline Tourniquet pressure $(\mathrm{mmHg})$ & 432.3/450/[350-550] \\
\hline \multicolumn{2}{|l|}{ Bone graft } \\
\hline Autologous bone & $6(4.72)$ \\
\hline Allograft bone & $11(8.67)$ \\
\hline OsteoSet & $7(5.51)$ \\
\hline Without & $103(81.1)$ \\
\hline Internal fixation & \\
\hline
\end{tabular}

Table 1 (continued)
Table 1 (continued)

\begin{tabular}{lc}
\hline Demographic & $\begin{array}{c}\text { Value } \\
(\mathrm{n} / \mathrm{mean}, \text { median and range })\end{array}$ \\
\hline Locking plate & $114(89.76)$ \\
Anatomic plate & $13(10.24)$ \\
Bleeding after tourniquet deflation & \\
Yes & $27(21.26)$ \\
No & $100(78.74)$ \\
Drainage & \\
Drainage strip & $30(23.62)$ \\
Rubber drainage tube & $5(3.94)$ \\
Without & $92(72.44)$ \\
\hline
\end{tabular}

BMI, body mass index.

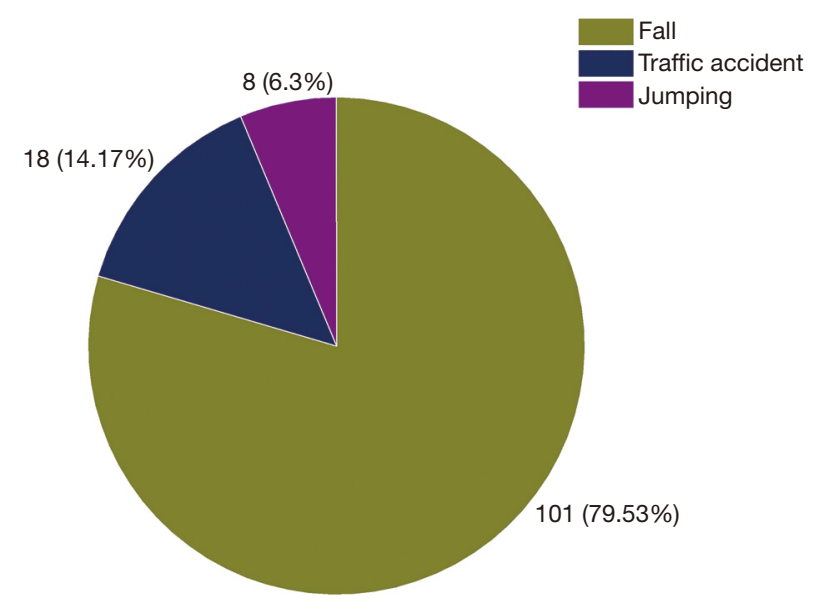

Figure 1 Trauma mechanism.

syndrome (Figure 3).

Time to operative intervention of the participants ranged from 2 to 7 days (average of 4.7 days). A total of 93 $(73.23 \%)$ cases received treatment within the first week, and 4 cases 1 week later (Figure 4). It took 75-135 min to perform the surgical procedures (mean time: $102.1 \mathrm{~min}$ ). Soft tissue dissection was performed using a conventional scalpel in 44 (34.65\%) participants and an electronic scalpel in $83(65.35 \%)$ participants. Tourniquet pressure exerted on participants was controlled within $350-550 \mathrm{mmHg}$, with a mean pressure of $432.3 \mathrm{mmHg}$. Bone grafting was applied to participants when necessary, among which $6(4.72 \%)$ cases received autogenous bone grafting, 11 


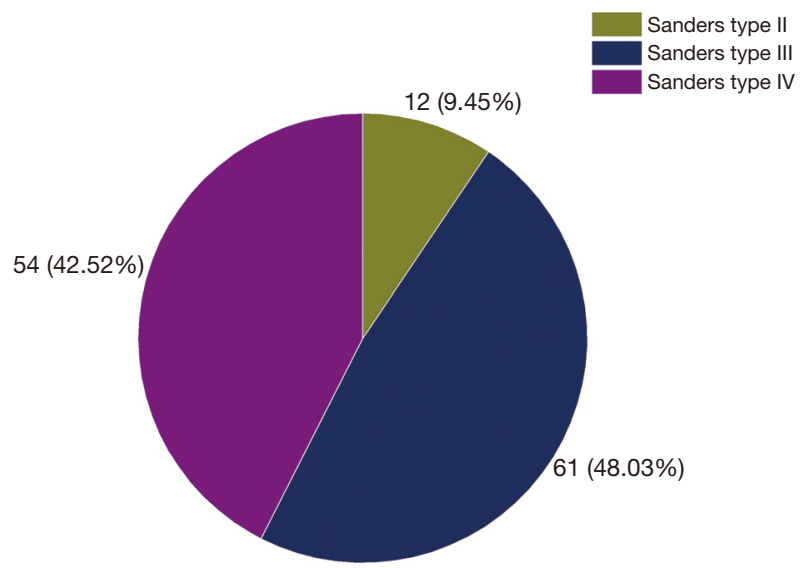

Figure 2 Sanders classification.

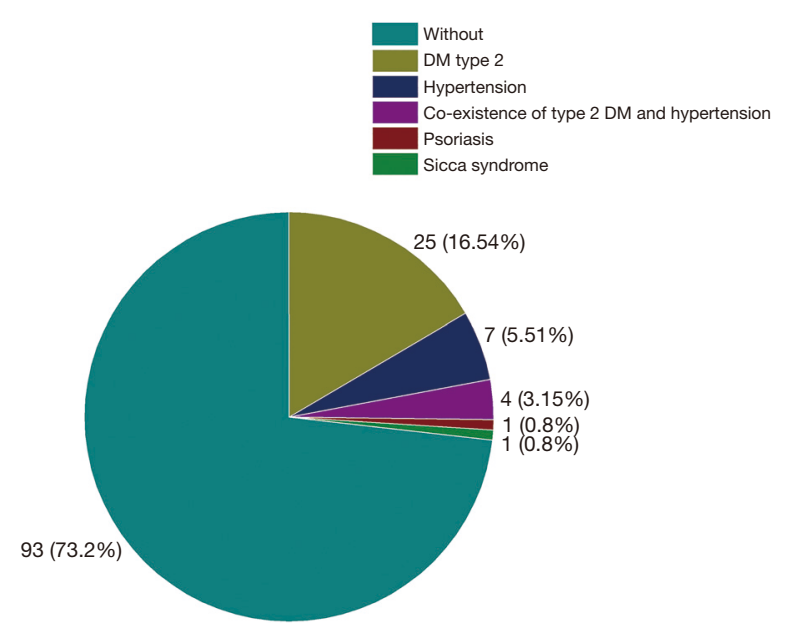

Figure 3 Co-morbidity.

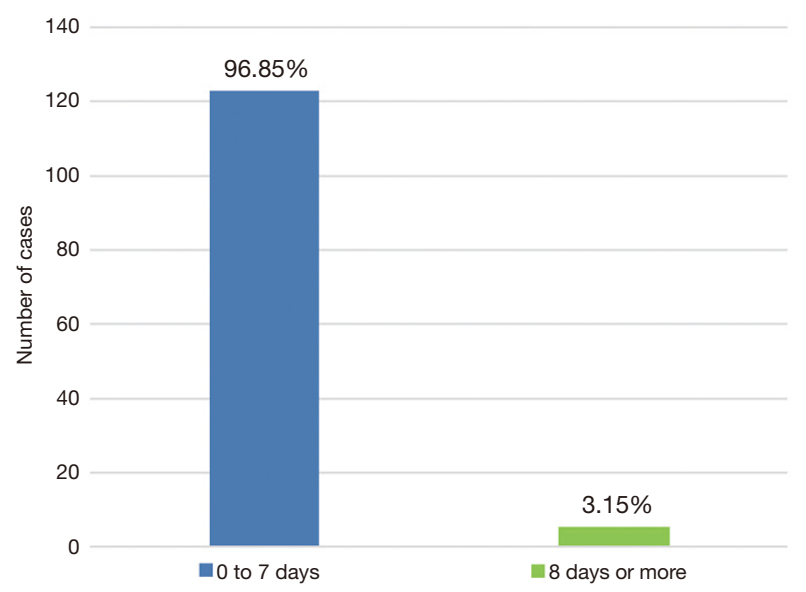

Figure 4 Time to surgery.

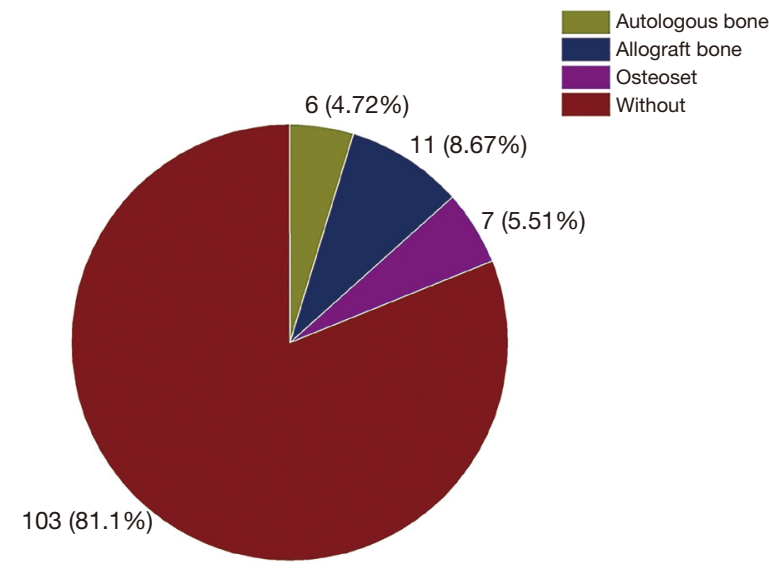

Figure 5 Bone grafting.

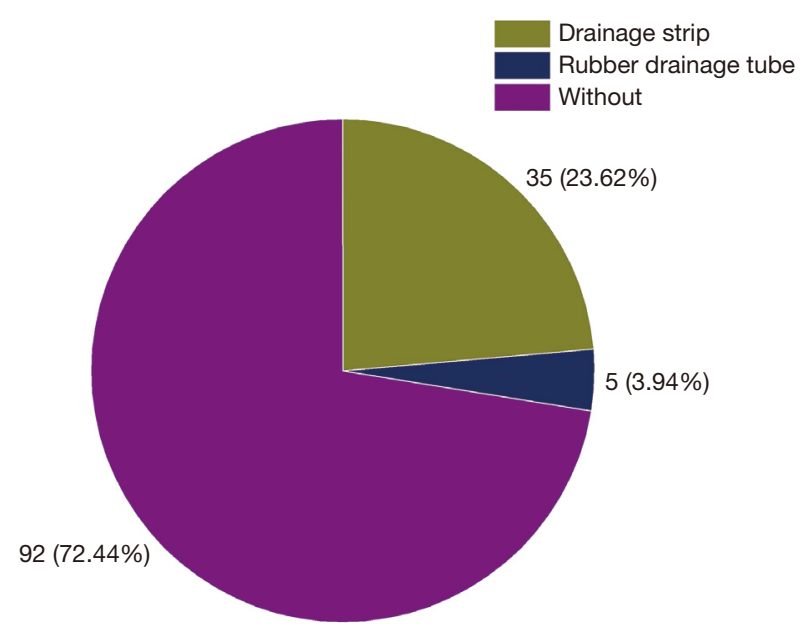

Figure 6 Drainage.

(8.67\%) received allograft bone grafting, and 7 (5.51\%) received OsteoSet (Wright Medical, Memphis, TN, USA) grafting (Figure 5). Internal fixation involved a locking plate on $114(89.76 \%)$ cases and anatomical plate on 13 (10.24\%). When the tourniquets were deflated, bleeding occurred in $27(21.26 \%)$ cases. In total, 35 cases were treated with drainage at the end of the operation, among which $30(23.62 \%)$ were with drainage strip and $5(3.94 \%)$ with a rubber drainage tube, respectively (Figure 6).

All participants received the standard surgical debridement, intravenous antibiotic therapy, and/or reconstruction in our hospital. Some 102 participants (80.32\%) were cured through complete debridement, antibiotic therapy, and with or without flap transplantation, and 15 participants (11.81\%) 
received retreatment abovementioned after relapse and were cured; 10 participants $(7.87 \%)$ received OsteoSet bone grafting in addition to the abovementioned therapies and were cured.

\section{Discussion}

There is currently an insufficiency of literature associated with calcaneal osteomyelitis. Limited references have reported that calcaneal osteomyelitis contributes only a small part of all reported bone infections (10). Although ORIF via an extensible lateral L-shaped approach is recognized as a gold standard treatment for calcaneus fracture, this surgical protocol may also induce the complication of wound infection, with an incidence of $2-15 \%$. The incidence of osteomyelitis has accounted for $1-4 \%$ of closed fracture complications (11). Calcaneal osteomyelitis is likely to result in partial or total calcanectomy, or more severely, amputation (10). Therefore, due to its limb-threatening nature, it is important to understand the epidemiology and clinical features of osteomyelitis following surgery for calcaneal fracture. In a recent study, we made a demographic description of all the participants. Males were the majority $(81.89 \%)$ when the inclusion criteria were the same. Our results were consistent with two current meta-analyses that osteomyelitis was a predominantly male disease $(12,13)$. Despite the truth the calcaneus osteomyelitis mainly affected males, it was revealed that women aged $\geq 40$ years were more likely to be affected [19 out of $23(72.61 \%)$ ] (data not shown). Out of the 127 cases, there were 93 cases $\geq 40$ years $(73.23 \%$ ) (data not shown). We considered that older adults were prone to osteomyelitis because they had a weaker tolerance for surgery and poorer ability to resist disorders that lead to infection, such as diabetes mellitus and orthopedic surgeries. A study on the surgical outcomes of intraarticular calcaneal fractures found that patients aged $>30$ years had poor outcomes compared with those under 30 years, thus leading to complication (14). Additionally, age $>65$ years is an important risk factor of calcaneus osteomyelitis (15). Healthy patients who develop osteomyelitis following a traumatic injury have the highest chance of recovering at young age (8). According to the counts of various trauma mechanism, a fall from height $(79.53 \%)$ became the main origin of calcaneus fracture, followed by traffic accident (14.17\%), and jumping (6.3\%). We speculated that there could be predisposing influences at the national level: China actively engages in infrastructure construction, and males comprise the major labor force.

The Sanders classification, which shows number of displaced fracture fragments and fracture line, is widely used to help stratify patients and thereby assist in modifying potential surgical interventions. The findings of Sanders classification suggested that most fractures were type III (48.03\%) or type IV (42.52\%), representing the severity and complexity caused by traumatic injury. Sanders type IV can result in severe comminuted fracture and lateral calcaneal wall rupture, aggravating the surrounding soft tissue contusion and increasing the difficulty of intraoperative reduction. Furthermore, complex fractures need prolonged operating time, which is another risk factor of wound complications with or without osteomyelitis $(6,16)$. There were $25(19.69 \%)$ cases accompanied by type 2 diabetes mellitus, 7 (5.51\%) by hypertension, and 1 each by psoriasis or sicca syndrome $(0.8 \%)$. Notably, diabetes mellitus itself, in addition to open calcaneal fractures, hematogenous seeding, and surgical site infections, is the most common risk factor of osteomyelitis and the commonest co-morbidity of the osteomyelitis cohort (17). It is likely that any comorbidity increases the chance of calcaneus osteomyelitis following ORIF. Patients with co-morbidities might be immunocompromised to avoid infection. Worse still, specific medications for co-morbidities are likely to affect patients' general condition due to pharmacokinetics that might influence complications following ORIF. Notably, diabetes mellitus alone is the largest driver of the increase in osteomyelitis incidence estimated to be approximately $0.3 \%$ per year (13).

The mean time to surgery in our study was 4.7 days, which was shorter than the 8.2 days reported by Cao et al. (18), while comparable to the 5.2 days demonstrated by Court-Brown (19). There is evidence that delay of operation may increase the infection rate (6), however, surgery must be delayed due to associated soft tissue swelling and the best intervention time is $7-14$ days after the original fracture. Visible skin wrinkling and no remaining pitting edema indicates positive surgical intervention may be safely implemented (11). In our study, most participants were treated within the first week following trauma and surgeries were performed depending on the general condition of participants, and local soft tissue conditions. The mean operating time in the present study was $102.1 \mathrm{~min}$, while it was $153 \mathrm{~min}$ in a study conducted by Al-Mudhaffar (6). Abidi et al. found that operating time was related to the occurrence of calcaneal osteomyelitis (20). 
When conducting surgical procedures, surgeons selected a conventional or electronic scalpel to strip soft tissue according to individual patient condition. Electronic scalpel was used on 83 cases $(65.35 \%)$, and conventional scalpel 44 cases (34.65\%). The electronic scalpel was regarded as a satisfactory surgical tool as it has been verified with a significant role in reducing blood loss and surgery duration (21). However, electronic scalpels might also increase the incidence of complications related to the surgical wound (21).

Applying a tourniquet for surgery provides a bloodless surgical field $(22,23)$. In our study, inflation spectrum was $350-550 \mathrm{mmHg}$, with a mean pressure of $432.3 \mathrm{mmHg}$. Although a previous study reported that tourniquets could induce complications like nerve injury, pain, venous thromboembolism, and so on (23), few studies have demonstrated the relationship between osteomyelitis occurrence and tourniquet pressure.

Bone grafting is commonly used during surgical procedures for fractures with acute or chronic osteomyelitis related bone loss, non-unions, malunions, and bony lesions to augment bone regeneration and provide structural support. Although bone grafting is recognized as an efficient, reliable, and promising orthopedic method, some studies have reported infectious complications associated with this procedure. In addition, bone grafting requires more operating time due to the determination of material, size, volume, and structure of graft appropriate to the defect (24-26). Conventionally, autologous bone is considered the optimal material since it is capable of meeting all necessary components including osteoconduction, osteoinduction, and osteogenesis of bone regeneration (27), and of avoiding histoincompatibility. Despite these superior advantages, the supply of autologous bone is limited and the donor site may suffer complications like the irritation of the sural nerve. Allograft is osteoconductive with reduced osteoinductivity and is available in various forms. Although allograft bypasses the harvesting quantity problems associated with autograft, it is still insufficient to meet clinical demands, and more importantly, has potential for transmission of infective agents (28). Bone graft substitutes, in particular calcium phosphate and recombinant human bone morphological proteins, are used in particular scenarios, for instance, the reconstruction of large bone defects (24). Bone graft substitutes can generate, when combined with bone morphogenetic protein (BMP), osteoinductive and osteogenic properties. In our investigation, due to various etiology and Sanders classification, options of bone grafting were adapted to the participants' needs. Consequently, there were $6(4.71 \%)$ cases which received autologous bone, 11 (8.67) of allograft, and 7 (5.51) of OsteoSet for grafting.

The internal fixation was performed through the usage of 2 types of plates: locking plate and anatomical plate. Case counts of the 2 types were $114(89.76 \%)$ and 13 (10.24\%), respectively. Both of these fixations can be expected to acquire good clinical efficacy. The option of internal fixation was based on factors such as fractures' state, comorbidity, and skin condition. Theoretically, a locking plate has a potential advantage in osteoporotic bone, provides sufficient strength to resist pullout, and this fixation allows screws to improve the stability of construction and facilitate bridging fixation, helping to maintain the reduced calcaneus morphology $(29,30)$. In particular, the locking plate is fit for Sanders type II and III fractures (31). An anatomical plate was specially designed for calcaneus fracture and could be tailored and modified intraoperatively. Nevertheless, a locking plate is costlier than anatomical plate. Both fixations may face the problematic complication of wound healing $(32,33)$.

A meta-analysis publicized in 2014 found no significant difference between early and delayed tourniquet release in blood loss (34). Another study reported early tourniquet release might decrease the risk of complication (35). Thus, tourniquets used in our surgical procedures were deflated early before wound closure. The outcome showed a total of $27(21.26 \%)$ cases bled after tourniquet deflation. Another report revealed that an increase in total blood loss and operation time occurred after early tourniquet release (36). Unnecessary blood loss probably aggravated the poor calcaneal blood supply, resulting in an unfavorable prognosis.

Wound drainage was applied according to the wound condition: $30(23.62 \%)$ cases were drained with a drainage strip, 5 (3.94\%) with rubber drainage tube, and 92 (72.44\%) without. It has been demonstrated that local drainage after surgery assists the surgical incision healing process, if necessary (37). However, whether drainage assists in calcaneus osteomyelitis requires confirmation through further study.

\section{Conclusions}

Our recent study showed that calcaneus osteomyelitis following traumatic calcaneus fracture occurred predominantly in young men. A fall from height was the most frequent trauma mechanism. The presence of severe calcaneus fracture, Sanders type III (48.03\%) and type IV $(42.52 \%)$, were the common fracture types in this population group. Despite successful developments in 
the surgical intervention of calcaneus fracture, calcaneus osteomyelitis following ORIF after calcaneus fracture still remains a problematic challenge. Understanding the frequency, distribution, and clinical features of calcaneal osteomyelitis following calcaneus fracture may help to minimize the occurrence of osteomyelitis. Future multicenter studies with large samples are needed to further understand the epidemiology and characteristics of calcaneal osteomyelitis following calcaneus fracture.

\section{Acknowledgments}

Funding: This study was supported by grants from the National Natural Science Foundation of China (No. 81603644), Zhejiang Province Public Welfare Technology Application Research Project (LGF21H270004), Medical Science and Technology Project of Zhejiang Province (2020RC048, 2021KY600), and Chinese Medicine Research Program of Zhejiang Province (2020ZQ006, 2021ZB060).

\section{Footnote}

Reporting Checklist: The authors have completed the STROBE reporting checklist. Available at http://dx.doi. org/10.21037/apm-21-208

Data Sharing Statement: Available at http://dx.doi. org/10.21037/apm-21-208

Conflicts of Interest: All authors have completed the ICMJE uniform disclosure form (available at http://dx.doi. org/10.21037/apm-21-208). The authors have no conflicts of interest to declare.

Ethical Statement: The authors are accountable for all aspects of the work in ensuring that questions related to the accuracy or integrity of any part of the work are appropriately investigated and resolved. All procedures performed in this study involving human participants were in accordance with the Declaration of Helsinki (as revised in 2013). The study was approved by Ethics committee of Tongde Hospital of Zhejiang Province (No.: 2015016). Individual consent for this retrospective analysis was waived.

Open Access Statement: This is an Open Access article distributed in accordance with the Creative Commons Attribution-NonCommercial-NoDerivs 4.0 International License (CC BY-NC-ND 4.0), which permits the non- commercial replication and distribution of the article with the strict proviso that no changes or edits are made and the original work is properly cited (including links to both the formal publication through the relevant DOI and the license). See: https://creativecommons.org/licenses/by-nc-nd/4.0/.

\section{References}

1. Zheng W, Xie L, Xie H, et al. With versus without bone grafts for operative treatment of displaced intra-articular calcaneal fractures: A meta-analysis. Int J Surg 2018;59:36-47.

2. Vicenti G, Carrozzo M, Solarino G, et al. Comparison of plate, calcanealplasty and external fixation in the management of calcaneal fractures. Injury 2019;50 Suppl 4:S39-S46.

3. Vosoughi AR, Shayan Z, Salehi E, et al. Agreement between Sanders classification of intraarticular calcaneal fractures and assessment during the surgery. Foot Ankle Surg 2020;26:94-7.

4. Cristine Mildred M, Juan Esteban H, Caroline R, et al. Functional evaluation of surgically-treated intra-articular fractures of the calcaneus. Rev Bras Ortop 2008;43:482-9.

5. Dhillon MS, Bali K, Prabhakar S. Controversies in calcaneus fracture management: a systematic review of the literature. Musculoskelet Surg 2011;95:171-81.

6. Al-Mudhaffar M, Prasad CV, Mofidi A. Wound complications following operative fixation of calcaneal fractures. Injury 2000;31:461-4.

7. Brucato MP, Wachtler MF, Nasser EM. Osteomyelitis of the Calcaneus With Pathologic Fracture. J Foot Ankle Surg 2019;58:591-5.

8. McCann MJ, Wells A. Calcaneal Osteomyelitis: Current Treatment Concepts. Int J Low Extrem Wounds 2020;19:230-5.

9. Fukuda T, Reddy V, Ptaszek A J. The infected calcaneus. Foot Ankle Clin 2010;15:477-86.

10. Alcaraz P, Aubran C, Jaoua S, et al. Calcaneal osteomyelitis due to fistulization of an ulcerated rheumatoid nodule. Joint Bone Spine 2006;73:102-4.

11. Clare MP, Sanders RW. Calcaneal fractures. FussSprungg 2007;5:58-73.

12. Jiang N, Ma YF, Jiang Y, et al. Clinical Characteristics and Treatment of Extremity Chronic Osteomyelitis in Southern China: A Retrospective Analysis of 394 Consecutive Patients. Medicine (Baltimore) 2015;94:e1874.

13. Kremers HM, Nwojo ME, Ransom JE, et al. Trends in the epidemiology of osteomyelitis: a population-based study, 
1969 to 2009. J Bone Joint Surg Am 2015;97:837-45.

14. Diranzo-García J, Bertó-Martí X, Castillo-Ruiperez L, et al. Treatment of intraarticular calcaneal fractures by reconstruction plate. Results and complications of 86 fractures. Rev Esp Cir Ortop Traumatol 2018. [Epub ahead of Print]. doi: 10.1016/j.recot.2018.01.010

15. Sabater-Martos M, Sigmund IK, Loizou C, et al. Surgical Treatment and Outcomes of Calcaneal Osteomyelitis in Adults: A Systematic Review. J Bone Jt Infect 2019;4:146-54.

16. Wu K, Wang C, Wang Q, et al. Regression analysis of controllable factors of surgical incision complications in closed calcaneal fractures. J Res Med Sci 2014;19:495-501.

17. Waibel FWA, Klammer A, Götschi T, et al. Outcome after surgical treatment of calcaneal osteomyelitis. Foot Ankle Int 2019;40:562-7.

18. Cao H, Li YG, An Q, et al. Short-Term Outcomes of Open Reduction and Internal Fixation for Sanders Type III Calcaneal Fractures With and Without Bone Grafts. J Foot Ankle Surg 2018;57:7-14.

19. Court-Brown CM, Schmied M, Schutte BG. Factors affecting infection after calcaneal fracture fixation. Injury 2009;40:1313-5. Erratum in: Injury 2011;42:725.

20. Abidi NA, Dhawan S, Gruen GS, et al. Wound-healing risk factors after open reduction and internal fixation of calcaneal fractures. Foot Ankle Int 1998;19:856-61.

21. Ribeiro GH, Kerr LM, Haikel RL, et al. Modified radical mastectomy: a pilot clinical trial comparing the use of conventional electric scalpel and harmonic scalpel. Int J Surg 2013;11: 496-500.

22. Tuncali B, Boya H, Kayhan Z, et al. Tourniquet pressure settings based on limb occlusion pressure determination or arterial occlusion pressure estimation in total knee arthroplasty? A prospective, randomized, double blind trial. Acta Orthop Traumatol Turc 2018;52:256-60.

23. Mcmillan TE, Gardner T, Jhonstone AJ. Current concepts intourniquet uses. Surgery (Oxford) 2020;38:139-42.

24. Dimitriou R, Jones E, Mcgonagle D, et al. Bone regeneration: current concepts and future directions. BMC Med 2011;9:66.

25. Patel JC, Watson K, Joseph E, et al. Long-term complications of distal radius bone grafts. J Hand Surg Am 2003;28:784-8.

26. Diaz-Dilernia F, Slullitel PA, Onativia JI, et al. Impaction Bone Grafting or Uncemented Modular Stems for the Treatment of Type B3 Periprosthetic Femoral Fractures? A Complication Rate Analysis. J Arthroplasty 2019;34:2051-7.
27. Bauer TW, Muschler GF. Bone graft materials. An overview of the basic science. Clin Orthop Relat Res 2000;(371):10-27.

28. Safoury Y. Free vascularized fibula for the treatment of traumatic bone defects and nonunion of the forearm bones. J Hand Surg Br 2005;30:67-72.

29. Ocalan E, Ustun CC, Aktuglu K. Locking plate fixation versus antegrade intramedullary nailing for the treatment of extra-articular distal femoral fractures. Injury 2019;50 Suppl 3:55-62.

30. Jordan RW, Chapman A, Buchanan D, et al. The role of intramedullary fixation in ankle fractures - A systematic review. Foot Ankle Surg 2018;24:1-10.

31. Long C, Fang Y, Huang FG, et al. Sanders II-III calcaneal fractures fixed with locking plate in elderly patients. Chin J Traumatol 2016;19:164-7.

32. Han L, Hu Y, Quan R, et al. Treatment of Neer IIb Distal Clavicle Fractures Using Anatomical Locked Plate Fixation With Coracoclavicular Ligament Augmentation. J Hand Surg Am 2017;42:1031-1036.e1.

33. Herlyn A, Brakelmann A, Herlyn PK, et al. Calcaneal fracture fixation using a new interlocking nail reducescomplications compared to standard locking plates - Preliminaryresults after 1.6 years. Injury 2019;50:63-8.

34. Zhang P, Liang Y, He J, et al. Timing of tourniquet release in total knee arthroplasty: A meta-analysis. Medicine (Baltimore) 2017;96:e6786.

35. Zhang $W$, Liu A, Hu D, et al. Effects of the timing of tourniquet release in cemented total knee arthroplasty: a systematic review and meta-analysis of randomized controlled trials. J Orthop Surg Res 2014;9:125.

36. Wong S, Irwin MG. Procedures under tourniquet. Anaesthesia \& Intensive Care Medicine 2018;19:155-8.

37. Figueiredo J, Côrte-Real N, Martinho C, et al. Influence of local drainage on calcanealfractures' surgical treatment complications. Foot and Ankle Surgery 2017;23:12-3.

(English Language Editor: J. Jones)

Cite this article as: Huang K, Guo Q, Zhu Y. The epidemiology and clinical features of calcaneus osteomyelitis following calcaneus fracture: a retrospective study of 127 cases. Ann Palliat Med 2021;10(3):3154-3161. doi: 10.21037/apm-21208 